Dörenberg, V.E.T., Veer, A.J.E. de, Francke, A.L., Embregts, P.J.C.M., Nieuwenhuizen, M. van, Frederiks, B.J.M. Applying restrictive measures in the care of adolescents with mild intellectual disabilities: attitudes of support staff and policy implications. Journal of Policy and Practiee in 7 Intellectual Disabilities: 2018, 15(1), 26-35 nivel

\begin{tabular}{|l|l|}
\hline $\begin{array}{l}\text { Postprint } \\
\text { Version }\end{array}$ & 1.0 \\
\hline Journal website & http://onlinelibrary.wiley.com/doi/10.1111/ippi.12223/abstract \\
\hline Pubmed link & \\
\hline DOI & $10.1111 /$ jppi.12223 \\
\hline
\end{tabular}

This is a NIVEL certified Post Print, more info at http://www.nivel.eu

\title{
Applying Restrictive Measures in the Care of Adolescents With Mild Intellectual Disabilities: Attitudes of Support Staff and Policy Implications
}

\author{
ViviAnNe E. T. Dörenberg ${ }^{1}$, ANKe J. E. DE VEeR ${ }^{2}$, ANNEKE L. FrANCKE ${ }^{1,2}$, PETRI J. C. M. \\ EMBREGTS $^{3}$, MAROESJKA VAN NIEUWENHUIJZEN ${ }^{1}$, BRENDA J. M. FREDERIKS $^{1}$
}

1. VU University Medical Centre Amsterdam, the Netherlands

2. NIVEL Netherlands Institute for Health Services Research, the Netherlands

3. Tilburg University, The Netherlands, and HAN University of Applied Sciences, The Netherlands, and Dichterbij Innovation \& Science, the Netherlands

\begin{abstract}
Research suggests that restrictive measures are widely used on adolescents with mild intellectual disabilities. In the Netherlands, restrictive measures are defined as all measures that limit the freedom of a person. In most countries, legislation and policies that seek to reduce the use of restrictive measures focus on seclusion and mechanical and physical restraints. The study aimed to investigate the extent to which restrictive practices are used in the care of adolescents with mild intellectual disabilities while also exploring the attitudes of support staff toward these interventions. A survey study was done among a nationally representative Dutch research sample consisting of support staff. A structured questionnaire was completed by 195 staff members (response of 68.7\%) working in settings providing care for people with intellectual disabilities. The measures generally used by staff members who work with adolescents with mild intellectual disabilities involved restricting the freedom of movement and socalled social restrictions (such as limiting the use of mobile phones). Nearly all respondents considered restrictive measures to be justified in the case of danger, physical aggression, or sexually abusive behavior (87.8-96.8\%). Frequently mentioned reasons for using restrictive measures were averting or avoiding danger (90.4 and 83.0\%, respectively) and calming the adolescent (63.8\%). Although seclusion and mechanical and physical restraints were generally considered most intrusive, staff members were aware that social restrictions could also be instrusive. The fact that current policies do not address these measures makes support staff question the lawfulness of their actions. As well as staff training to reduce the use of restrictive measures, rules, and legislation
\end{abstract}


Dörenberg, V.E.T., Veer, A.J.E. de, Francke, A.L., Embregts, P.J.C.M., Nieuwenhuizen, M. van, Frederiks, B.J.M. Applying restrictive measures in the care of adolescents with mild intellectual disabilities: attitudes of support staff and policy implications. Journal of Policy and Practiee in 7 Intellectual Disabilities: 2018, 15(1), 26-35

are also needed to clarify the options and limits to using such measures in the professional care of adolescents with mild intellectual disabilities.

\section{INTRODUCTION}

In recent years, policymakers in the Netherlands have become increasingly interested in the extent to which restrictive measures are used in the care of adolescents (ages 12-23) with mild intellectual disabilities (ID) and how to reduce such use. Internationally, there is evidence that restraints are widely used to manage challenging behavior in young people with ID (Menon, Baburaj, \& Bernard, 2012). In the Netherlands, the general public became aware of the wide use of restrictive measures on adolescents with mild ID in 2011 when the Evangelische Omroep (E.O.), a public broadcasting company, aired a documentary about an 18-year-old patient in a Dutch home for the disabled who spent part of his days tethered to a wall due to the danger he posed to others. The case sparked a national debate and highlighted the need for evidence-based guidance that incorporates clinical, ethical, and legal aspects of the use of restrictive measures in dealing with challenging behavior in adolescents with mild ID in residential care (Frederiks, 2011). So far, however, there has been little attention to this subject in academic research, whether in the Netherlands or abroad.

The Dutch Healthcare Inspectorate defines restrictive measures as "all measures whether verbal, physical, mechanical or medical - restricting a person's freedom" (Inspectie voor de Gezondheidszorg 2007; 2008). Thus, the Dutch Healthcare Inspectorate employs a broad definition of "restrictive practices" that is far more inclusive than that used in many other jurisdictions. Romijn and Frederiks (2012) made a comparison between a number of countries. In the United Kingdom, for example, the Deprivation of Liberty Safeguards (DoLS) were introduced in 2005 as an amendment to the Mental Capacity Act 2005. The DoLS specify a special procedure when clients who lack the capacity to consent to their care and treatment need to be deprived of their liberty in order to keep them safe from harm. DoLS are used for a wide range of deprivation measures. Two questions have to be answered to determine whether a person is being deprived of their liberty: (1) Is the person subject to continuous supervision and control? and (2) Is the person free to leave? In Australia, each state formulates its own definition of restrictive measures. In the Disability Act (2006) of the State of Victoria, for example, only two forms of restrictive measures are mentioned: chemical and physical restraints.

The term "restrictive measures" as used in this article covers a wide range of measures, ranging from house rules and surveillance technologies to measures such as physical or mechanical restraints and seclusion. The application of restrictive measures to people in residential care in general has been an ongoing topic of debate in academia, policy, and practice in many countries (Rickard, Chan, \& Merriman, 2013). As in most countries, the debate in the Netherlands initially focused on the use of pressure and coercion (defined as influence by threats and bribes). In recognition of the negative physical and psychological effects of coercion on both clients and staff, there has been a move toward policies aimed at reducing coercive measures. In the United Kingdom, for example, there is a focus on positive behavioural support (PBS) as an intervention model for reducing coercion (Gore et al., 2013). The advantage of PBS is that it combines the technology of behavioral intervention with the values of normalisation, human rights, and self-determination 
Dörenberg, V.E.T., Veer, A.J.E. de, Francke, A.L., Embregts, P.J.C.M., Nieuwenhuizen, M. van, Frederiks, B.J.M. Applying restrictive measures in the care of adolescents with mild intellectual disabilities: attitudes of support staff and policy implications. Journal of Policy and Practiee in 7 Intellectual Disabilities: 2018, 15(1), 26-35

to deliver effective person-centred support for people whose behavior challenges (PBS Competence Framework 2015). Thus, PBS results in enhanced well being and greater meaningful and valued participation by the client. Reduction in challenging behavior by the client is an additional gain.

The first policies in the Netherlands aimed at reducing the use of pressure and coercion originated in the field of psychiatry, with the definition of eight criteria for high quality care (Berghmans, Elfahmi, Goldsteen, \& Widdershoven, 2001). These criteria related to staff expertise in supporting and working with people undergoing treatment for psychiatric conditions, communication, reflection (thinking about goals and the impact of pressure and coercion), the process of care and adequate preconditions for creating the right conditions for high quality care. The criteria were implemented in 12 Dutch psychiatric institutions and brought about a significant change in organizational culture (Abma, Widdershoven, \& Lendemeijer, 2005). Similar criteria were subsequently drawn up for the disability services sector (Abma, Frederiks, van Hooren, Widdershoven, van Wijmen, \& Curfs, 2006). They included criteria relating, for example, to the ability of support staff to communicate with clients with ID. By then, the focus had shifted to the use of restrictive measures in a broader sense - encompassing both coercive measures and "restrictive" measures based on informed consent - and the Dutch government set up ongoing programmes to monitor restrictive practices in long-term care. This created a general awareness among staff that restrictive measures should be used only as a last resort when all other means have failed.

Staff nonetheless experience difficulty in reducing the use of restrictive measures. Restrictive measures are still routinely used despite current policies stressing that such measures should only be used as a last resort, a rapidly growing evidence base for methods that let staff reduce the seclusion of people with ID and the use of mechanical or physical restraints (Gaskin, McVilly, \& McGillivray, 2013; Luiselli, 2009; Williams, 2010) and the availability of potential alternatives (Dutch Health Care Inspectorate, 2012; McGill, Murphy, \& Kelly-Pike, 2009).

The goal of reducing the use of restrictive measures in the care of adolescents with mild ID presents particular problems. Such adolescents are characterized by limitations in their cognitive and social adaptive functioning (Schalock et al., 2010) and have a higher risk of developing serious emotional and behavioral problems (Dekker, Koot, van der Ende, \& Verhulst, 2002), as well as antisocial and delinquent behavior (Douma, Dekker, de Ruiter, Tick, \& Koot, 2007). It is known from earlier research that certain factors within the social environment of a client, such as negative staff attitudes, contribute to the persistence of behavioral problems in people with a cognitive impairment and can sometimes even trigger them (Embregts, Didden, Huitink, \& Schreuder, 2009; Hastings, 1997; Hastings \& Remington, 1994). Conversely, clients' behavioral problems also affect the emotional well being and actions of the staff looking after them and may sometimes create feelings of fear, anger, and annoyance among staff (Bromley \& Emerson, 1995; Hastings, 1995; Hatton, Brown, Caine, \& Emerson, 1995). Staff members who feel threatened by their clients' behavior are considerably less likely to comply fully with verbal or written care agreements (Allen \& Tynan, 2000). They may then revert to measures that restrict their clients' freedom. Various studies (Allen, Lowe, Brophy, \& Moore, 2009; Matson \& Boisjoli, 2009) have shown that clients with mild ID who 
Dörenberg, V.E.T., Veer, A.J.E. de, Francke, A.L., Embregts, P.J.C.M., Nieuwenhuizen, M. van, Frederiks, B.J.M. Applying restrictive measures in the care of adolescents with mild intellectual disabilities: attitudes of support staff and policy implications. Journal of Policy and Practiee in 7 Intellectual Disabilities: 2018, 15(1), 26-35

demonstrate aggressive and antisocial behavior are more likely to be subjected to restrictive measures than clients who do not behave in this way.

Little is known, however, about the extent of restrictive practices in the care of adolescents with mild ID, or about how staff view the use of restrictive measures with such clients. Earlier research on staff perceptions in the disability services sector was limited to restraint procedures (Cunningham, McDonnell, Easton, \& Sturmey, 2003), physical interventions (Fish \& Culshaw, 2005; Hawkins, Allen, \& Jenkins, 2005), and the restraint and seclusion of adults (Mérineau-Côté \& Morin, 2013); this research also focused mainly on clinical aspects of the use of such measures. Policy may benefit from insight into restrictive practices in the care of adolescents with mild ID and staff perceptions on the subject. Understanding how staff view the use of restrictive measures in the care of such clients can help identify issues that need to be addressed.

For years, policymakers in many countries have focused on the use of seclusion and physical and mechanical restraints and on the assessment of danger and risk (Romijn $\&$ Frederiks, 2012). In this article, we will discuss whether there are any valid reasons for shifting the focus of policy and legislation in the case of adolescents with mild ID. To answer this question, we conducted a survey among support staff working with people with ID and explored what kinds of measures are generally used in the case of adolescents with mild ID and living in residential care. We also investigated staff views on defining, justifying, using, and reducing the use of restrictive measures in such clients. This survey aimed to gain insight into the use of restrictive measures in the care of adolescents with mild ID by addressing the following questions:

1. What restrictive measures do staff members generally use in the care of adolescents with mild ID?

2. To what extent does consensus exist among staff that these measures restrict freedom?

3. In what situations do staff members consider employing restrictive measures?

4. Which goals do staff members see as justifying the use of restrictive measures?

5. How do staff members believe the use of restrictive measures can be reduced?

Based on the preliminary results of prior research (Dörenberg, Embregts, van Nieuwenhuijzen, \& Frederiks, 2013a; 2013b; the "larger study" mentioned in the subsection "Procedure"), support staff might use a wide range of restrictive measures in the care of adolescents with mild ID and would do so not just to avert danger but also for so-called pedagogical and therapeutic reasons. In the Netherlands, the term "pedagogical" is frequently used in the care of adolescents with mild ID and refers to something support staff would do to support their clients' development. Furthermore, consensus among support staff might be greater in the case of seclusion and mechanical or physical restraints than in case of other measures that can be applied to adolescents with mild ID since Dutch policies and legislation focus on these measures and awareness among support staff might therefore be higher. 
Dörenberg, V.E.T., Veer, A.J.E. de, Francke, A.L., Embregts, P.J.C.M., Nieuwenhuizen, M. van, Frederiks, B.J.M. Applying restrictive measures in the care of adolescents with mild intellectual disabilities: attitudes of support staff and policy implications. Journal of Policy and Practiee in 7 Intellectual Disabilities: 2018, 15(1), 26-35

\section{METHOD}

\section{Procedure}

A postal questionnaire was sent to support staff, followed if necessary by two reminders (after two and four weeks). The survey was part of a larger study on the use and reduction of restrictive measures in the care of adolescents with mild ID (Dörenberg et al., 2013a, 2013b). This study was carried out against the background of current and future Dutch regulations on care and coercion. For this reason, the questionnaire had a strong legal emphasis, focusing on aspects such as definitions, and justifications in the use of restrictive measures in the care of adolescents with mild ID.

As the protocol for the questionnaire study did not involve imposing any interventions or actions, Dutch legislation does not require its approval by an ethics committee (under the Medical Research Involving Human Subjects Act; see www.ccmo-online.nl). All respondents received a letter informing them of the aim and goal of the study. Participation in the study was voluntary, while responses were anonymous and nontraceable to individuals.

\section{Participants}

The survey sample was a preexisting, nationally representative research sample of support staff in the Netherlands (a subgroup of the Nursing Staff Panel). Members of this panel are recruited via a random sample of the population of Dutch healthcare employees provided by the Dutch Employee Insurance Agency. This agency is responsible for social security payments and registers all employees in the Dutch healthcare sector. Healthcare employees in this random sample were asked to participate in research for various purposes. Staff delivering direct care who agreed to this request were then invited to become members of the panel. This procedure promotes a diverse composition of the panel in terms of age, sex, region, and employer. Participation in the panel is voluntary and anonymous. For this study, social-worker support staff working in the disabilities services sector were asked to complete the questionnaire. The Dutch disabilities services sector covers a range of services for people with ID in large residential institutions, for people with ID living in small-scale community houses and for people with ID living in ordinary homes. Social-worker support staff in this sector have either an associate degree or a bachelor degree.

A total of 284 people were sent a questionnaire which was completed by 195 respondents (response: $68.7 \%$ ). They worked with clients living in a community house $(45.6 \%)$, in an inpatient setting $(35.9 \%)$, in their own home $(10.8 \%)$, or with their family $(9.2 \%)$. The majority of the respondents were female $(88.2 \%)$ and aged over $45(56.5 \%)$. The average age of the respondents was higher than the average age of the total population of staff in organizations caring for people with ID. Although all the respondents worked with people with ID, only one third $(33.7 \%)$ worked specifically with adolescents with mild ID (IQ 50-70; IQ 70-85 and additional social adjustment problems).

\section{Questionnaire}

The construction of the questionnaire to measure the perceptions of social-worker support staff regarding restrictive measures in the care of adolescents with mild ID involved several steps. The questions in the questionnaire were based on an earlier questionnaire that had been shown to be valid and reliable in an earlier survey of 
Dörenberg, V.E.T., Veer, A.J.E. de, Francke, A.L., Embregts, P.J.C.M., Nieuwenhuizen, M. van, Frederiks, B.J.M. Applying restrictive measures in the care of adolescents with mild intellectual disabilities: attitudes of support staff and policy implications. Journal of Policy and Practiee in 7 Intellectual Disabilities: 2018, 15(1), 26-35

physical restraints (de Veer et al., 2009). This earlier questionnaire was derived from the results of a qualitative interview study. The validity of this earlier questionnaire was judged by experts in the field of restraint use and the survey results showed that the questions were easy to answer. Therefore, the questions in this earlier questionnaire were used for the current questionnaire on restrictive measures in the care of adolescents. The list of measures that are considered in the current questionnaire was adapted to make it applicable to adolescents with mild ID. The 45 measures that are mentioned in the current questionnaire were derived from qualitative group interviews (Dörenberg et al., 2013a); six group interviews were held with adolescents with mild ID and nine group interviews with professionals from three care organizations. The interviews were semistructured and focused on the use of restrictive measures in practice. This resulted in the list of 45 measures that could be perceived as restrictive, 24 situations in which restrictive measures could be considered, and 11 justifications. The draft questionnaire was tested for comprehensibility and completeness by four psychologists, two legal experts, three support staff members working in disability care services for adolescents with mild ID, and members of a group of stakeholders (including representatives of three care organizations for people with mild ID, a Dutch knowledge centre on mild ID and a Dutch institute for health services research). The experts were instructed to assess (1) the comprehensiveness of each question, (2) the comprehensiveness and the completeness of response categories, (3) the exhaustiveness of the questionnaire. This resulted in minor modifications to the questionnaire to enhance the comprehensiveness. The validity of the questionnaire was judged as good and there was no need to add new measures, situations, or justifications.

The structured questionnaire had closed-ended and open-ended questions and focused on (1) the respondents' background characteristics, (2) perceptions of the restrictiveness and use of measures, (3) beliefs about the justification and necessity of restrictive measures, and (4) perceptions of how certain measures are applied in practice. The current article focuses on the perceptions of the restrictiveness and use of measures, and on the perceived justification and need for restrictive measures.

To measure the use of restrictive measures, the respondent was presented with a list of 45 different measures. For each measure, the respondent was asked to indicate whether they applied it (yes/no). The 45 measures were grouped into six main categories: (1) general behavior rules and activities (eight measures, including "prohibition on entering into discussion with staff" and "mandatory times for clients to stay in their bedrooms"), (2) measures on the freedom of movement (14 measures, including "a separation room" and "prohibition on leaving the home"), (3) surveillance measures (five measures, such as "a camera"), (4) measures on social contacts and the use of media (seven measures, such as "controlling the use of the internet and social media"), (5) measures on the use of alcohol and drugs (six measures, such as "a smoking ban" and "urine tests"), and (6) other measures (five measures, such as "secret administration of medication").

The same list of measures was used to assess whether a measure was perceived as restricting someone's freedom. For each measure the respondent was asked whether they thought the measure restricted a person's freedom (yes/no).

To determine the situations in which support staff would consider restrictive measures necessary, 24 brief descriptions were given of a situation (such as "verbal aggression by a client towards a staff member"). For each situation, the respondent 
Dörenberg, V.E.T., Veer, A.J.E. de, Francke, A.L., Embregts, P.J.C.M., Nieuwenhuizen, M. van, Frederiks, B.J.M. Applying restrictive measures in the care of adolescents with mild intellectual disabilities: attitudes of support staff and policy implications. Journal of Policy and Practiee in 7 Intellectual Disabilities: 2018, 15(1), 26-35

had to indicate whether this situation could be a trigger (yes/no) for considering a restrictive measure.

Additionally, a list of 11 possible justifications was presented to assess how staff members sought to justify the use of restrictive measures. These justifications included "to avert danger," "to ensure tranquillity or restore order in the group," and "to support the client." Respondents had to indicate whether they used these justifications when applying a restrictive measure (yes/no).

Finally, the respondents were asked whether they had any views on reducing the use of specific measures (yes/no). If so, they were asked to describe how this could be achieved (open question). The answers were categorized by one of the researchers.

\begin{abstract}
ANALYSIS
Descriptive statistics were calculated using Stata 12.1. Social-worker support staff in the Netherlands are trained to work with different severities of ID and different age groups. However, the extent of their experience working with adolescents with mild ID might influence their perceptions of restrictive measures. This is particularly likely regarding the actual use of restrictive measures (research question 1). Some measures (such as restricting gaming via the internet) are of particular relevance to adolescents with mild ID. Analyses of the use of the measures were therefore restricted to respondents actually working with adolescents with mild ID. For research questions 2 (Table 1, final column), 3 (Table 2), and 4 (Table 3) the results are reported for all respondents, because in general no statistically significant differences were found between the answers of staff members working with adolescents with mild ID and those working with other groups (chi-squared tests, $p<0.01)$.
\end{abstract}

[TABLE 1] [TABLE 2][TABLE 3]

\title{
RESULTS
}

Use of Measures and the Perceived Restrictiveness (Research Questions 1 and 2) Table 1, first column, shows the measures applied by at least $20 \%$ of the respondents working with adolescents with mild ID; this was the case for 26 of the 45 measures listed in the questionnaire. Of these 26 measures, six concerned restricting the freedom of movement and six concerned restrictions on social contacts and the use of media ("social restrictions"). Commonly used measures were house and group rules $(90.5 \%)$ and the presence of staff members in the residence $(61.9 \%)$. The other measures were mentioned by between $20.6 \%$ (physical control techniques such as an armlock) and $46.0 \%$ (a ban on the use of soft drugs in or around the residence) of the staff members.

As the second column in Table 1 shows, commonly used measures (house and group rules, and the presence of staff members in the residence) were not generally perceived as restricting freedom. This also applied to reward systems. Of the measures applied by at least $20 \%$ of the respondents, consensus on the restriction of freedom was highest for being obliged to stay in your room as a collective measure during the day (67.9\%), prohibitions on going outside alone $(66.8 \%)$, locking the front door during the day (66.8\%), physical control techniques such as an armlock 
Dörenberg, V.E.T., Veer, A.J.E. de, Francke, A.L., Embregts, P.J.C.M., Nieuwenhuizen, M. van, Frederiks, B.J.M. Applying restrictive measures in the care of adolescents with mild intellectual disabilities: attitudes of support staff and policy implications. Journal of Policy and Practiee in 7 Intellectual Disabilities: 2018, 15(1), 26-35

(69.4\%), checking e-mail (73.6\%) and prohibitions on having contact with specific people $(72.0 \%)$.

As expected, consensus on the restriction of freedom was highest for seclusion and mechanical restraints and related measures. These measures were applied by fewer than $20 \%$ of the respondents working with adolescents with mild ID and are therefore not shown in Table 1. For example, using a harness to tether a client to a wall was seen as restricting freedom by $89.1 \%$ of the staff members. Closed confinement in a room not specifically designed for this purpose, such as a chill-out room, was also considered a restriction of freedom by $89.1 \%$ of the staff members, followed by seclusion in a cell specifically designed for seclusion $(88.6 \%)$, closed confinement in a room specifically designed for confinement $(88.6 \%)$, and closed confinement in the adolescent's bedroom $(88.1 \%)$. Consensus was lower for confinement with an open door, varying from 30.6 to $42.0 \%$. Asked which measures they considered to be the most restrictive of the 45 measures, staff members considered seclusion in a cell $(70.6 \%)$ and the use of mechanical restraints (59.9\%) to be the most restrictive. These results may indicate a relationship between use of the measures and the extent to which these measures were perceived as restricting freedom.

\section{Situations Eliciting Restrictive Measures (Research Question 3)}

For a majority (64.9\%) of the respondents, the situation was of importance in determining whether a restrictive measure could be applied. Table 2 lists a number of situations that may occur in the residential care of adolescents with mild ID. Staff members indicated which situations would lead them to consider a restrictive measure. Nearly all staff members would consider using a restrictive measure if the safety of the adolescent, fellow residents or personnel was at risk, or if the adolescent was physically aggressive or sexually abusive. In situations involving excessive consumption of substances (alcohol or drugs), 70.9\% of staff members would consider a restrictive measure, while experimental use of substances would prompt $23.3 \%$ of the staff members to consider a restrictive measure. Failure to comply with personal agreements or personal rules or with house or group rules was seen by $27.5 \%$ and $24.3 \%$, respectively, of the staff members as a reason for considering a restrictive measure. For $61.9 \%$, a request by a client for a restrictive measure constituted sufficient reason to consider such a measure. If, however, a client's legal representative or guardian requested a restrictive measure, only $34.9 \%$ and $22.8 \%$, respectively, of the staff members saw this as sufficient reason to consider such a measure. If a client was verbally aggressive to other clients or a staff member, $57.7 \%$ and $43.4 \%$, respectively, of the staff members saw this as a reason for considering a restrictive measure. Staff members did not see the mere fact that a client started arguing with them as a reason for considering a restrictive measure. Similarly, staff members did not regard staff shortages and lack of time as sufficient reason for considering restrictive measures.

\section{Justifications for Restrictive Measures (Research Question 4)}

Table 3 shows that averting danger and avoiding future danger were frequently mentioned as justifications for applying a restrictive measure. The majority $(63.8 \%)$ of the staff members also said that restrictive measures were applied in order to calm the adolescent. A wish to discipline the client or to restore authority was not generally perceived as valid justification for applying a restrictive measure. By 
Dörenberg, V.E.T., Veer, A.J.E. de, Francke, A.L., Embregts, P.J.C.M., Nieuwenhuizen, M. van, Frederiks, B.J.M. Applying restrictive measures in the care of adolescents with mild intellectual disabilities: attitudes of support staff and policy implications. Journal of Policy and Practiee in 7 Intellectual Disabilities: 2018, 15(1), 26-35

contrast, $28.2 \%$ stated that the need to restore order within the group justified the use of a restrictive measure.

\section{Views on Reducing the Use of Restrictive Measures (Research Question 5)}

The majority $(65 \%)$ of staff members had no views on how to reduce the use of restrictive measures. Only $35 \%$ had views on this subject, specifically with regard to reducing restrictions on clients' freedom of movement. Apart from seclusion, and mechanical and physical restraints, the measure of "not allowing a client to start arguing with staff" was also frequently mentioned as a restriction that could be used less often or avoided.

In the answers to the open questions on reducing the use of restrictive measures, staff members referred to more personnel (36\% of the respondents who answered the question) or smaller group sizes (11\%), better qualified personnel (31\%), a greater focus on the relationship between the adolescent and the staff member (34\%), and anticipating situations (instead of responding in an ad hoc manner) (25\%). Also care that takes each individual's needs and wishes into account is expected to reduce the number of restrictive measures (36\%). Interestingly, few staff members gave a shortage of staff or lack of time as reasons for applying restrictive measures in practice. Frequently mentioned reasons were wanting to protect clients and to prevent them from endangering others. This suggests that having additional staff and focusing more on the relationships with clients could in many cases prevent the dangerous situations arising that could lead to a client's freedom of movement being restricted.

\section{DISCUSSION}

\section{Defining Restrictive Measures}

In many cases, restrictive measures are applied on the basis of informed consent. Informed consent is obtained in accordance with guidelines from the field of medical ethics and the rules and regulations for agreeing to medical treatment. Therefore, explicit informed consent from a client or a client's designated responsible proxy (e.g., parents or a legal guardian) is required prior to applying restrictive measures (except in emergency situations). In the Netherlands, at the age of 12, a child is given the right to decide on medical treatment (wilsbekwaam ter zake). At the age of 16, a child becomes legally capacitated (handelingsbekwaam) when it comes to medical treatment, although legally still considered a minor. This is no difference in the case of adolescents with mild ID. The starting point is that they consent to their care or support plans and to any proposed medical treatment, including the application of restrictive measures. When care professionals consider them unable to consent to the plan or certain aspects of treatment (wilsonbekwaam ter zake), a proxy is allowed to consent. In the Netherlands, the proxy decision-making power for the treatment of adolescents in the ages of 12-18 lies with the parents or a legal guardian. For the treatment of adolescents aged 18 years and above this power lies with a court appointed representative ("mentor" or "curator"), with a representative previously appointed by the client, or with a family member (mostly the parents). However, their consent expires at the moment the adolescent demonstrates opposition. Written informed consent is neither required by law nor needed in practice, although in practice, restrictive measures are usually part of a signed care or support plan. Support staff seemed to be aware that measures based on informed consent, so-called 
Dörenberg, V.E.T., Veer, A.J.E. de, Francke, A.L., Embregts, P.J.C.M., Nieuwenhuizen, M. van, Frederiks, B.J.M. Applying restrictive measures in the care of adolescents with mild intellectual disabilities: attitudes of support staff and policy implications. Journal of Policy and Practiee in 7 Intellectual Disabilities: 2018, 15(1), 26-35

voluntary measures, could also restrict freedom, but Dutch law does not consider these measures to be a restriction of freedom (given the client agrees with the measures being applied or previously agreed with the applying of restrictive measures and does not oppose at the time of the measures actually being applied). This means there is no legal obligation to report their use to the Dutch Healthcare Inspectorate, and this in turn results in a lack of supervision. According to the rules and regulations for agreeing to medical treatment, such a measure is regarded as restrictive only if a client demonstrates opposition at the time of its being applied. In the United Kingdom, the definition of "restrictive measures" is much broader. Measures without resistance can also be seen as a deprivation of liberty. This applies in situations in which a person is subject to continuous supervision and control and is not free to leave.

Recognizing the risk when restrictive measures are used without explicit reporting requirements, the Dutch Healthcare Inspectorate urged organizations in the field to develop a national registration system covering the use of restrictive measures and subsequently, in 2016, the government funded a research project for the uniform registration of restrictive measures in the care of people with intellectual disability. The Netherlands is not the only country in which the importance of registration is emphasized (Romijn \& Frederiks, 2012). A registration system could also help define restrictive measures since there are many different definitions of such measures circulating within the field, and most of these do not include voluntary restrictive measures. How the term is interpreted seems also to depend on the care context as the survey results showed a lack of agreement in this respect. For example, interventions such as sending clients to their room or forbidding them to go out alone are sometimes seen as part of a child's upbringing and consequently not considered to be restrictive. The same goes for therapeutic interventions such as restricting the use of computers or mobile phones in order to remove negative incentives. These measures are sometimes seen as part of the treatment. More research is needed to determine which factors in the care context influence the extent to which a measure is perceived as restricting freedom.

Although staff seemed to have a broad interpretation of what constituted a restrictive measure, the survey results also showed that they did not have a clear notion of the extent to which measures restricted an adolescent's freedom. Although they generally seemed to interpret the concept broadly, many of them were - as expected - still unclear about measures commonly applied for pedagogical reasons, such as forbidding clients to go out alone, and measures intended to achieve a specific treatment aim, such as limiting and restricting social contacts. The issue of applying measures for pedagogical reasons was explicitly raised (Dörenberg \& Frederiks, 2012) during the drafting of the Care and Coercion Bill (wetsvoorstel Zorg en $d$ wang), a proposed legal framework for the Netherlands covering the use of restrictive measures in caring for people with intellectual disabilities and people in psychogeriatric care. This issue was also raised in the drafting of the Compulsory Mental Healthcare Bill (wetsvoorstel Verplichte geestelijke gezondheidszorg), a proposed legal framework for the Netherlands governing coercion in the case of people undergoing treatment for psychiatric conditions. There are signs that although these bills have made staff more aware of the range and restrictive nature of the measures that they apply in day-to-day practice, the actual meaning of the concept of "restrictive measures" remains unclear. The Care and Coercion Bill simply states that 
Dörenberg, V.E.T., Veer, A.J.E. de, Francke, A.L., Embregts, P.J.C.M., Nieuwenhuizen, M. van, Frederiks, B.J.M. Applying restrictive measures in the care of adolescents with mild intellectual disabilities: attitudes of support staff and policy implications. Journal of Policy and Practiee in 7 Intellectual Disabilities: 2018, 15(1), 26-35

so-called pedagogical measures no longer exist, whereas the Compulsory Mental Healthcare Bill sets out an elaborate framework of measures, initially including those used on pedagogical grounds. Practitioners would benefit from a clear definition of restrictive measures, with a broad interpretation of the concept, and from a framework for application that makes it clear whether and, if so, to what extent a measure can be regarded as permitted in specific circumstances.

\section{Justifying Restrictive Measures}

Applying a broad definition of "restrictive measures" will shift the focus toward the ways in which measures can be justified. The law states the circumstances in which care professionals are justified in using restrictive measures. A distinction is made in Dutch law between collective measures and individual measures. Collective measures, such as house rules, are justified if they are used as a means of keeping order. Care professionals do not need to obtain individual informed consent before using collective measures. However, house rules should at least be determined in consultation with the clients. In contrast to collective measures, individual measures need the informed consent of the individual client or his/her legal representative. As long as a measure does not constitute a breach of a person's right to liberty under Article 5 of the European Convention on Human Rights and the individual does not resist the measure at any time, informed consent by law constitutes sufficient justification for restricting freedom. In the event of resistance, a measure is justified only if it is applied to a legally incapacitated individual and is necessary to protect their health or to prevent damage to others. These rules also apply to adolescents with mild ID, although in their case the UN Convention on the Rights of Persons with Disabilities and the UN Convention on the Rights of the Child do provide additional protection by stating, for example, that in all actions concerning children the best interests of the child shall be a primary consideration. Under the Psychiatric Hospitals (Compulsory Admissions) Act (Wet Bijzondere opnemingen in psychiatrische ziekenhuizen), special rules on restrictive measures apply if an individual is involuntarily admitted to a psychiatric hospital on the grounds of mental illness or intellectual disability. These rules cover the use of restrictive measures as part of their treatment (involuntary or otherwise), the use of specific restrictive measures in emergency situations for up to seven days and the use of measures restricting their freedom of movement and contact, in addition to house rules.

The survey shows that practitioners often consider using a restrictive measure if safety is threatened. Given this, it is not surprising that many respondents give the wish to avert danger and prevent a dangerous situation from arising as reasons for using restrictive measures. Interestingly, however, $63.8 \%$ of the staff members also mentioned calming the client down as one of the aims, whereas most staff members (76.2\%) did not actually regard a client's agitation as sufficient cause to consider a restrictive measure. Under the present legislation, the only circumstances in which restrictive measures are regarded as a justified means of managing challenging behavior in a client are aggression toward other people and self-harming/aggression toward themselves. Future legislation in this field currently looks unlikely to result in much change in this respect. The Compulsory Health Care Bill admittedly allows scope to include measures in house rules if these measures are needed to safeguard the pedagogical conditions prevailing within an institution. The Care and Coercion Bill, however, does not provide for this. Lastly, the fact that few staff members 
Dörenberg, V.E.T., Veer, A.J.E. de, Francke, A.L., Embregts, P.J.C.M., Nieuwenhuizen, M. van, Frederiks, B.J.M. Applying restrictive measures in the care of adolescents with mild intellectual disabilities: attitudes of support staff and policy implications. Journal of Policy and Practiee in 7 Intellectual Disabilities: 2018, 15(1), 26-35

would consider restrictive measures for punitive or other disciplinary reasons is remarkable. This may relate, however, to the fact that the types of measures considered by staff members in such circumstances were not always regarded as restricting clients' freedom.

\section{Using and Reducing the Use of Restrictive Measures}

The results showed that measures restricting freedom were not just considered as a response to aggression or other behavioral problems. It would seem that some measures used by those caring for adolescents with mild ID were applied in order to calm clients down or otherwise to prevent them from behaving in a way that interferes with treatment (e.g., using alcohol or drugs). These were not the measures that staff members saw as offering potential for reduced use. It is understandable that staff members respond to behavior constituting a risk to an adolescent's development, and this may explain why they had difficulty in conceiving measures applied for pedagogical reasons as being restrictive. About half (55.3\%) of all the staff members surveyed regarded pedagogical interventions, such as sending a client to his or her room or setting a client apart from other clients, as restrictive, whereas the other half did not regard such measures as restrictive $(24.2 \%)$ or had no opinion on the subject (20.5\%). The term "restrictive" generally has negative connotations, whereas applying pedagogical measures is usually seen as part of looking after adolescents and helping them to develop. Such measures can nevertheless be equally intrusive, and careful consideration consequently needs to be given before they are applied. Additional research on the relationship between the use of these measures and circumstances that elicit them may further clarify if and how such measures can be reduced.

\section{Limitations of the Survey}

A possible limitation of this study is that young staff members were under represented in our sample. Young staff members may respond differently because they are closer to the clients in terms of age. Further research could give more insight into how the characteristics and former experiences of a staff member influence their perception of the use of restrictive measures in the care of adolescents with mild ID. Although all the respondents worked in the care of people with intellectual disabilities, not all of them worked with adolescents with mild ID. This may be why some of them may have been less able to empathize with the day-to-day workplace situation and the specific client group. A more detailed analysis of the responses found little difference, however, between the answers given by staff members working with the specific client group and those given by staff members not working with such people. The only clear difference was in the answers to the question about which measures staff members applied in their day-to-day work. These answers showed, not unexpectedly, that respondents working with the specific client group were more likely to apply restrictive measures relating to the use of media and substances than those not working with such clients.

Finally, the participants were healthcare workers and social workers working in either health or social care settings within the disabilities services sector. However, in many countries including the Netherlands (e.g., also USA, Australia, UK), the majority of children $(<12)$ and adolescents $(>12)$ with ID are cared for within the special education system where restrictive practices are also regularly employed (Pilling, McGill, \& Cooper, 2007; Sperling \& Wijnands, 2015; Villani, Parsons, 
Dörenberg, V.E.T., Veer, A.J.E. de, Francke, A.L., Embregts, P.J.C.M., Nieuwenhuizen, M. van, Frederiks, B.J.M. Applying restrictive measures in the care of adolescents with mild intellectual disabilities: attitudes of support staff and policy implications. Journal of Policy and Practiee in 7 Intellectual Disabilities: 2018, 15(1), 26-35

Church, \& Beetar, 2012). In some cases (e.g., due to severe behavioral problems during (early) adolescence) adolescents with mild ID end up in health or social care settings, in the youth care setting or even in the penal setting, where they are confronted with a wide range of restrictive measures. In the Netherlands, the legal frameworks for using restrictive measures within these settings differ greatly, while the restrictive practices as such may not. Therefore, comparing restrictive practices within the health and social care settings with those within the educational setting, the youth care setting and maybe even the penal setting is an interesting topic for future research.

\section{CONCLUSION}

The perception of what constitutes a restrictive measure plays a key role in raising awareness among staff of the use of restrictive measures and in subsequently reducing the use of such measures. This study found that, in contrast to the provisions in current legislation, staff applied a broad interpretation of what constitutes a restrictive measure. Although measures such as seclusion and mechanical and physical restraints were generally thought to be intrusive for clients, staff members seemed to be aware that social restrictions, too, could be intrusive. The additional comments suggest, however, that staff members struggled with the use — or rather the justified use — of restrictive measures applied on pedagogical grounds, such as restricting the use of computers and mobile phones, and specifically the internet. Current policies do not address the issue of these "pedagogical" measures, and this made staff members question the lawfulness of their actions. This is why these measures in particular need to be addressed in legislation and policy. Moreover, the risk of such measures being applied arbitrarily is higher because staff members were generally less aware of the restrictive nature of these measures. Staff training may be beneficial in reducing the use of restrictive measures, provided it includes efforts to increase staff members' awareness of restrictive measures and the potential effects that such measures may have on clients and staff, as well as the discussion of possible alternatives. In addition, rules and policies are needed to clarify the options and limitations applicable to the use of restrictive measures in the professional care of adolescents with mild ID. After all, the fact that legislation does not make specific provisions for certain restrictive measures does not preclude staff from applying them.

\section{Acknowledgments}

The survey was part of a larger study funded by Stichting Innovatie Alliantie (SIA). SIA had no involvement in conducting this study, and nor was it involved in preparing this article.

\section{REFERENCES}

Abma, T. A., Frederiks, B. J. M., Hooren, R. H., van Widdershoven, G. A. M., van Wijmen, F. C. B., \& Curfs, L. M. G. (2006). Kwaliteitscriteria voor vrijheidsbeperking in de zorg voor mensen met een verstandelijke beperking. Maastricht, the Netherlands: Maastricht University.

Abma, T. A.,Widdershoven, G. A. M., \& Lendemeijer, B. (Eds.) (2005). Dwang en drang in de psychiatrie: de kwaliteit van vrijheidsbeperkende maatregelen. Utrecht, the Netherlands: Lemma. 
Dörenberg, V.E.T., Veer, A.J.E. de, Francke, A.L., Embregts, P.J.C.M., Nieuwenhuizen, M. van, Frederiks, B.J.M. Applying restrictive measures in the care of adolescents with mild intellectual disabilities: attitudes of support staff and policy implications. Journal of Policy and Practiee in 7 Intellectual Disabilities: 2018, 15(1), 26-35

Allen, D., Lowe, K., Brophy, S., \& Moore, K. (2009). Predictors of restrictive reactive strategy use in people with challenging behaviour. Journal of Applied Research in Intellectual Disabilities, 22, 159-168.

Allen, D., \& Tynan, H. (2000). Responding to aggressive behaviour: Impact of training on staff members' knowledge and confidence. Mental Retardation, 38, 97-104.

Berghmans, R., Elfahmi, D., Goldsteen, M., \& Widdershoven, G. (2001). Kwaliteit van dwang en drang in de psychiatrie: eindrapport. Utrecht, the Netherlands: GGZ Nederland (Dutch Association of Mental Health and Addiction Care).

Bromley, J., \& Emerson, E. (1995). Beliefs and emotional reactions of care staff working with people with challenging behaviour. Journal of Intellectual Disability Research, 39, 341-352.

Cunningham, J., McDonnell, A., Easton, S., \& Sturmey, P. (2003). Social validation data on three methods of physical restraint: Views of consumers, staff and students. Research on Developmental Disabilities, 24, 307-316.

Dekker, M. C., Koot, H. M., van der Ende, J., \& Verhulst, F. C. (2002). Prevalence of psychopathology in children and adolescents with and without intellectual disability. Journal of Child Psychology and Psychiatry and Allied Disciplines, 43, 1087-1098.

Dörenberg, V. E. T., Embregts, P. J. C. M., van Nieuwenhuijzen, M., \& Frederiks, B. J. M. (2013a). Oog voor vrijheid: kwaliteitscriteria voor vrijheidsbeperking in de zorg voor jongeren en jongvolwassenen met een lichte verstandelijke beperking. Leiden, the Netherlands: University of Applied Sciences Leiden.

Dörenberg, V. E. T., Embregts, P. J. C. M., van Nieuwenhuijzen, M., \& Frederiks, B. J. M. (2013b). Web van regels: een juridische analyse van vrijheidsbeperking in de zorg voor jongeren en jongvolwassenen met een lichte verstandelijke beperking. Achtergrondstudie bij het rapport 'oog voor Vrijheid'. Leiden, the Netherlands: University of Applied Sciences Leiden.

Dörenberg, V. E. T., \& Frederiks, B. J. M. (2012). The legal position of vulnerable people in the future: Improving or going backwards? European Journal of Health Law, 19, 485-502.

Douma, J. C. H., Dekker, M. C., Ruiter, K. P., de, Tick, N. T., \& Koot, H. M. (2007). Antisocial and delinquent behaviors in youth with mild to borderline disabilities. American Journal on Mental Retardation, 112, 207-220.

Embregts, P. J. C. M., Didden, R., Huitink, C., \& Schreuder, N. (2009). Contextual variables affecting aggressive behavior in individuals with mild to borderline intellectual disabilities who live in a residential facility. Journal of Intellectual Disability Research, 53, 255-264.

Fish, R., \& Culshaw, E. (2005). The last resort? Staff and client perspectives on physical intervention. Journal of Intellectual Disabilities, 9, 93-107.

Frederiks, B. (2011). Brandon is meer dan een gevaar: Juridische houdbaarheid van vrijheidsbeperking rammelt. Medisch Contact, 66, 548-550.

Gaskin, C. J., McVilly, K. R., \& McGillivray, J. A. (2013). Initiatives to reduce the use of seclusion and restraints on people with developmental disabilities: A systematic review and quantitative synthesis. Research in Developmental Disabilities, 34, 3946-3961.

Gore, N. J., McGill, P., Toogood, S., Allen, D., Hughes, J. C., Baker, P., . . Denne, L. D. (2013). Definition and scope for positive behavioural support. International Journal of Positive Behavioural Support, 3, 14-23.

Hastings, R. P. (1995). Understanding factors that influence staff responses to challenging behaviours: An exploratory interview study. Mental Handicap Research, 8, 296-320.

Hastings, R. P. (1997). Staff beliefs about the challenging behaviours of children and adults with mental retardation. Clinical Psychology Review, 17, 775-790.

Hastings, R. P., \& Remington, B. (1994). Rules of engagement: Toward an analysis of staff responses to challenging behavior. Research in Developmental Disabilities, 15, 279-298.

Hatton, C., Brown, R., Caine, A., \& Emerson, E. (1995). Stressors, coping strategies and stress related outcomes among direct care staff in staffed houses for people with learning disabilities. Mental Handicap Research, 8, 252-271.

Hawkins, S., Allen, D., \& Jenkins, R. (2005). The use of physical interventions with people with intellectual disabilities and challenging behaviour: The experiences of service users and staff members. Journal of Applied Research in Intellectual Disabilities, 18, 19-34.

Inspectie voor de Gezondheidszorg (Dutch Health Care Inspectorate). (2007).

Toetsingskader onderzoek 'Zorg voor Vrijheid' in de Verstandelijk Gehandicaptenzorg en Verpleeghuis- en Verzorgingshuiszorg: Terugdringen van vrijheidsbeperkende 
Dörenberg, V.E.T., Veer, A.J.E. de, Francke, A.L., Embregts, P.J.C.M., Nieuwenhuizen, M. van, Frederiks, B.J.M. Applying restrictive measures in the care of adolescents with mild intellectual disabilities: attitudes of support staff and policy implications. Journal of Policy and Practiee in 7 Intellectual Disabilities: 2018, 15(1), 26-35

maatregelen en bevorderen van good practices. Utrecht, the Netherlands: Inspectie voor de Gezondheidszorg.

Inspectie voor de Gezondheidszorg (Dutch Health Care Inspectorate). (2008). Zorg voor vrijheid: terugdringen van vrijheidsbeperkende maatregelen kán en moet. Den Haag, the Netherlands: Inspectie voor de Gezondheidszorg.

Inspectie voor de Gezondheidszorg. (2012). Extra inspanning noodzakelijk voor terugdringen vrijheidsbeperking in langdurige zorg: Meer inzet externe deskundigen en betere focus op afbouw. Utrecht, theNetherlands: Inspectie voor de Gezondheidszorg.

Luiselli, J. K. (2009). Physical restraint of people with intellectual disabilities: A review of implementation reduction and elimination procedures. Journal of Applied Research in Intellectual Disabilities, 22, 126-134.

Matson, J. L., \& Boisjoli, A. B. (2009). Restraint procedures and challenging behaviours in intellectual disability: An analysis of causative factors. Journal of Applied Research in Intellectual Disabilities, 22, 111-117.

McGill, P., Murphy, G., \& Kelly-Pike, A. (2009). Frequency of use and characteristics of people with intellectual disabilities subject to physical interventions. Journal of Applied Research in Intellectual Disabilities, 22, 152-158.

Menon, K., Baburaj, R., \& Bernard, S. (2012). Use of restraint for the management of challenging behaviour in children with intellectual disabilities. Advances in Mental Health and Intellectual Disabilities, 6, 62-75.

Mérineau-Côté, J., \& Morin, D. (2013). Restraint and seclusion: The perspective of service users and staff members. Journal of Applied Research in Intellectual Disabilities, 26, 1-11.

Positive Behavioural Support (PBS) Coalition UK. (2015). Positive Behavioural Support: A Competence Framework. Available on http://pbscoalition.blogspot.co.uk/

Pilling, N., McGill, P., \& Cooper, V. (2007). Characteristics and experiences of children and young people with severe intellectual disabilities and challenging behaviour attending 52week residential special schools. Journal of Intellectual Disability Research, 51, 184-196.

Rickard, E. D., Chan, J., \& Merriman, B. (2013). Issues emanating from the implementation of policies on restraint use with people with intellectual disabilities. Journal of Policy and Practice in Intellectual Disabilities, 10, 252-259.

Romijn, A., \& Frederiks, B. J. M. (2012). Restriction on restraints in the care for people with intellectual disabilities in the Netherlands: Lessons learned from Australia, UK and the United States. Journal of Policy and Practice in Intellectual Disabilities, 9, 127-133.

Schalock, R. L., Borthwick-Duffy, S. A., Bradley, V. J., Buntinx, W. H. E., Coulter, D. L., Craig, E. M., \& Yeager, M. H. (2010). Intellectual disability: Definition, classification and systems of supports (11th ed.). Washington, DC: American Association on Intellectual and Developmental Disabilities.

Sperling, J., \& Wijnands, F. (2015). Zachte heelmeesters. . .: De toelaatbaarheid van fysiek handelen tegen leerlingen door onderwijspersoneel. School en Wet, 5-10.

de Veer, A. J. E., Francke, A. L., Buijse, R., \& Friele, R. D. (2009). The use of physical restraints in home care in the Netherlands. Journal of the American Geriatrics Society, 57, 1881-1886.

Villani, V. S., Parsons, A. E., Church, R. P., \& Beetar, J. T. (2012). A descriptive study of the use of restraint and seclusion in a special education school. Child and Youth Care Forum, 41, 295-309.

Williams, D. E. (2010). Reducing and eliminating restraint of people with developmental disabilities and severe behavior disorders: An overview of recent research. Research in Developmental Disabilities, 31, 1142-1148. 
Dörenberg, V.E.T., Veer, A.J.E. de, Francke, A.L., Embregts, P.J.C.M., Nieuwenhuizen, M. van, Frederiks, B.J.M. Applying restrictive measures in the care of adolescents with mild intellectual disabilities: attitudes of support staff and policy implications. Journal of Policy and Practiee in 7 Intellectual Disabilities: 2018, 15(1), 26-35

\section{TABLES}

Table 1. Measures applied by staff members working with adolescents with mild ID (percentages) and percentage of support staff members who perceive a measure as restricting freedom

\begin{tabular}{|c|c|c|}
\hline & 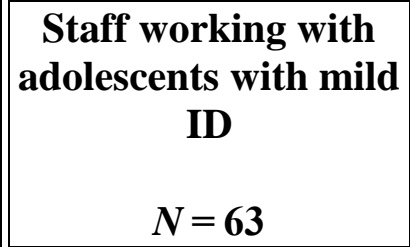 & $\begin{array}{l}\text { Total group of staff } \\
\qquad N=193\end{array}$ \\
\hline Measure & $\begin{array}{c}\text { \% who apply each } \\
\text { measure }\end{array}$ & $\begin{array}{c}\text { \% who perceive each } \\
\text { measure as restricting } \\
\text { freedom }\end{array}$ \\
\hline \multicolumn{3}{|l|}{ General behavior rules and activities } \\
\hline House and group rules & $90.5^{\mathrm{a}}$ & $24.4^{\mathrm{b}}$ \\
\hline Compulsory times for meals/showers/bed & 30.2 & 53.9 \\
\hline $\begin{array}{l}\text { Mandatory times for clients to be in their rooms } \\
\text { during daytime }\end{array}$ & 22.2 & 67.9 \\
\hline \multicolumn{3}{|l|}{ Measures regarding the freedom of movement } \\
\hline $\begin{array}{l}\text { Putting clients in their rooms without locking the } \\
\text { door }\end{array}$ & 42.9 & 30.6 \\
\hline $\begin{array}{l}\text { Forbidding clients from going somewhere } \\
\text { (village/town, school, family/friends, etc.) alone }\end{array}$ & 42.9 & |66.8 \\
\hline $\begin{array}{l}\text { Holding clients by the arm and accompanying } \\
\text { them somewhere }\end{array}$ & 36.5 & |32.6 \\
\hline $\begin{array}{l}\text { Locking the front door of a group residence at } \\
\text { night without giving clients the key }\end{array}$ & 33.3 & |63.2 \\
\hline $\begin{array}{l}\text { Keeping the front door of a group residence } \\
\text { locked during daytime }\end{array}$ & 33.3 & |66.8 \\
\hline $\begin{array}{l}\text { Applying physical control techniques to clients } \\
\text { such as an armlock (hyperextending the arm) }\end{array}$ & 20.6 & |69.4 \\
\hline \multicolumn{3}{|l|}{ Surveillance measures } \\
\hline Presence of staff in the residence & 61.9 & 14.5 \\
\hline Centralized monitoring & 41.3 & 54.9 \\
\hline Doorbell control in client's room & 30.2 & 60.1 \\
\hline Door alarm & 25.4 & 61.7 \\
\hline \multicolumn{3}{|l|}{$\begin{array}{l}\text { Measures regarding social contacts and use of } \\
\text { media ("social restrictions") }\end{array}$} \\
\hline $\begin{array}{l}\text { Limits on use of computer, mobile or other } \\
\text { telephone, television, etc. }\end{array}$ & ||38.1 & ||53.4 \\
\hline Reading a client's post & 33.3 & 73.6 \\
\hline
\end{tabular}




\begin{tabular}{|c|c|c|}
\hline & 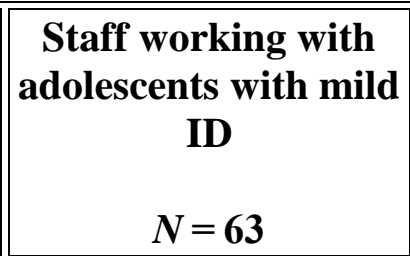 & $\begin{array}{l}\text { Total group of staff } \\
\qquad N=193\end{array}$ \\
\hline Measure & $\begin{array}{l}\text { \% who apply each } \\
\text { measure }\end{array}$ & $\begin{array}{c}\% \text { who perceive each } \\
\text { measure as restricting } \\
\text { freedom }\end{array}$ \\
\hline $\begin{array}{l}\text { Monitoring use of computer, mobile or other } \\
\text { telephone, television, etc. }\end{array}$ & ||31.8 & $\mid 50.8$ \\
\hline Prohibiting contact with specific people & 23.8 & 72.0 \\
\hline Visiting rules & 22.2 & 42.5 \\
\hline Monitoring use of the internet and social media & 30.2 & 50.3 \\
\hline \multicolumn{3}{|l|}{$\begin{array}{l}\text { Measures regarding the use of alcohol and } \\
\text { drugs }\end{array}$} \\
\hline $\begin{array}{l}\text { Prohibiting recreational use of soft drugs in or } \\
\text { around the residence }\end{array}$ & 46.0 & 43.5 \\
\hline Prohibiting alcohol on school/working days & 30.2 & 35.2 \\
\hline Prohibiting alcohol for clients under 18 & 27.0 & 26.4 \\
\hline $\begin{array}{l}\text { Specifying the maximum number of cigarettes } \\
\text { allowed to be smoked per day/week }\end{array}$ & 22.2 & ||61.7 \\
\hline \multicolumn{3}{|l|}{ Other measures } \\
\hline Reward system & 38.1 & 15.5 \\
\hline $\begin{array}{l}\text { Restricting a client financially (e.g., not allowing } \\
\text { cash machine use or use of cash machine without } \\
\text { permission) }\end{array}$ & 36.5 & 50.3 \\
\hline Giving a "hormonal shot" (contraception) & 22.2 & 28.5 \\
\hline
\end{tabular}

${ }^{\mathrm{a}}$ That is, $90.5 \%$ of the staff members working with adolescents with mild ID apply house and group rules.

${ }^{\mathrm{b}}$ That is, $24.4 \%$ of all the respondents see the use of house and group rules as restricting freedom. 
Dörenberg, V.E.T., Veer, A.J.E. de, Francke, A.L., Embregts, P.J.C.M., Nieuwenhuizen, M. van, Frederiks, B.J.M. Applying restrictive measures in the care of adolescents with mild intellectual disabilities: attitudes of support staff and policy implications. Journal of Policy and Practiee in 7 Intellectual Disabilities: 2018, 15(1), 26-35

Table 2. Situations in which a restrictive measure is considered

\begin{tabular}{|c|c|}
\hline & $N=189$ \\
\hline Situation & $\%$ \\
\hline Other clients' safety is threatened & 96.8 \\
\hline The client's own safety is at risk & 96.3 \\
\hline The client is physically aggressive to another person & 95.2 \\
\hline A staff member's safety is at risk & 92.1 \\
\hline The client displays deviant or problematic sexual behavior & 87.8 \\
\hline Excessive use of substances (alcohol, drugs) & 70.9 \\
\hline The client uses physical aggression on inanimate objects & 64.6 \\
\hline The client requests application of a measure & 61.9 \\
\hline The client is verbally aggressive to other clients & 57.7 \\
\hline Disruption to the order in the group & 57.7 \\
\hline The client is verbally aggressive to a staff member & 43.4 \\
\hline $\begin{array}{l}\text { A request for a measure by the legal representative (e.g., parents/guardian or } \\
\text { "'mentor") }\end{array}$ & || 34.9 \\
\hline The client's personal development is at risk & 33.3 \\
\hline The client is unable to deal with a situation effectively on his/her own & 28.6 \\
\hline $\begin{array}{l}\text { The client fails to comply with personal agreements or personal rules } \\
\text { applicable only to them }\end{array}$ & $\mid 27.5$ \\
\hline The client fails to comply with house or group rules & 24.3 \\
\hline The client is agitated & 23.8 \\
\hline Experimental use of substances (alcohol, drugs) & 23.3 \\
\hline Sexual contact between clients & 22.8 \\
\hline If the family guardian or supervisor asks for a measure to be applied & 22.8 \\
\hline If the client sets a bad example to other clients & 15.3 \\
\hline If too few staff are present to supervise & 4.8 \\
\hline If there is too little time for supervision & 3.2 \\
\hline If the client starts arguing & 0.5 \\
\hline
\end{tabular}


Dörenberg, V.E.T., Veer, A.J.E. de, Francke, A.L., Embregts, P.J.C.M., Nieuwenhuizen, M. van, Frederiks, B.J.M. Applying restrictive measures in the care of adolescents with mild intellectual disabilities: attitudes of support staff and policy implications. Journal of Policy and Practiee in 7 Intellectual Disabilities: 2018, 15(1), 26-35

Table 3. Goals of a restrictive measure

\begin{tabular}{|l|l||}
\hline \multicolumn{1}{|c|}{ Goal } & $\boldsymbol{N = 1 8 8}$ \\
\hline \hline \multicolumn{1}{|c|}{} & \% \\
\hline To avert danger to the client or another person & 90.4 \\
\hline \hline To prevent the client from getting into a dangerous situation & 83.0 \\
\hline \hline To calm the client down & 63.8 \\
\hline To support the client & 44.9 \\
\hline To protect the client from adverse influences from outside & 42.6 \\
\hline \hline To contribute to the client's personal development & 42.0 \\
\hline To prevent the client from becoming addicted & 40.4 \\
\hline To ensure tranquillity in the group or restore order to the group & 28.2 \\
\hline \hline To teach the client discipline & 5.9 \\
\hline To restore authority & 5.9 \\
\hline
\end{tabular}

